\title{
Luchas sociales en la configuración del Distrito Metropolitano de Quito entre 1992-2010
}

\author{
Social conflicts in the configuration of the Quito \\ Metropolitan Area in the period 1992-2010
}

\author{
Víctor Hugo Torres D. ${ }^{1}$ \\ vtorres@ups.edu.ec
}

\section{Resumen}

El texto interpreta las luchas contestarias en Quito durante el proceso de conformación del distrito metropolitano entre 1992-2010, destaca las relaciones heterónomas con el poder regional, las conexiones culturales entre las movilizaciones sociales y la hegemonía de las elites locales, y las disputas por los espacios públicos urbanos. Se analiza el ciclo de arranque, auge y crisis del movimiento barrial capitalino, considerando el peso relativo de lo barrial en la conformación del poder regional en la ciudad, lo que condiciona el episódico protagonismo de las organizaciones barriales y sus limitaciones en la disputa de la modernidad-colonial de la ciudad.

\section{Palabras clave}

Movimientos sociales, poder regional, espacios públicos, modernización-colonial urbana.

\begin{abstract}
The text interprets the struggles would social answer in Quito during the process of forming the metropolitan district between 1992-2010, it highlights the heterónomas relations with the regional power, cultural connections between social movements and the hegemony of local elites, and disputes over the urban public spaces. The starting cycle, boom and bust of the capital neighborhood movement is analyzed, considering the relative weight of the neighborhood in shaping the regional power in the city, which determines the episodic role of neighborhood organizations and their limitations in the dispute of the city colonial-modernity.
\end{abstract}

\section{Keywords}

Social movements, regional power, public spaces, city-colonial modernity.

Forma sugerida de citar: Torres D., Víctor Hugo (2016). Luchas sociales en la configuración del Distrito Metropolitano de Quito entre 1992-2010. Univeristas, XIV(24), pp. 63-82.

1 Doctor en Sociología. Candidato al Doctorado en Estudios Culturales Latinoamericanos. DocenteInvestigador UPS. 


\section{Introducción}

En este artículo se plantea una interpretación de las luchas contestatarias en Quito, durante el proceso de conformación del distrito metropolitano, esto es entre los años 1992-2010, cuando se aprobó y aplicó la Ley del Distrito Metropolitano de Quito con la que se consolidó el proceso de organización territorial metropolitano iniciado en los años sesenta, a través de la renovación y expansión urbana que integró ámbitos territoriales, dispersó actividades urbanas y concentró-fraccionó la propiedad territorial (Carrión, 1987, p. 86); con lo que en el curso de cinco décadas la ciudad pasó de la antigua forma pericéntrica asentada en 5188,8 ha, a una desbordada forma policéntrica extendida en 43 550,1 ha (Instituto de la Ciudad, 2012). El análisis de las luchas sociales se enfoca en el movimiento barrial, enfatizando en la heteronomía política que caracteriza las relaciones de los más de 400 barrios perifericos con la ciudad, en el papel de los simbolismos identitarios frente al poder regional, y en las disputas culturales del fraccionado espacio público capitalino.

El texto está divido en tres secciones: en la primera sección y a manera de marco referencial se reseña la racionalidad instrumental que está detrás de las organizaciones urbanas, particularmente de las organizaciones barriales, en el esfuerzo de inserción en la ciudad como respuesta a la segregación urbana que motivó al movimiento barrial. En la segunda sección, a manera de escenario, se plantea el acceso diferenciado de los actores colectivos a los espacios públicos quiteños, advirtiendo que las luchas barriales ocurrieron dentro de ciertos perímetros espaciales simbólicamente valorizados. Y en la tercera sección se sintetiza el ciclo del movimiento barrial capitalino, destacando las subjetividades identitarias que predominaron en los momentos de inicio, auge y decline de la lucha barrial.

En la caracterización de las luchas contestatarias de una sociedad desigual y excluyente como la quiteña, no son suficientes las explicaciones funcionalistas que a priori afirman la existencia de movimientos sociales activados ante la segregación y exclusión, o el surgimiento de las organizaciones poblacionales como aliadas de la clase obrera y alineadas con los intereses de los explotados en la ciudad ${ }^{2}$; si bien algo de esto puede haber, cabe ampliar

2 En los pocos estudios de las organizaciones barriales de los años setenta y ochenta se caracterizaban ortodoxamente a los pobladores como un subproletariado urbano, sus organizaciones eran consideradas como extensiones de las organizaciones sindicales, residuales en la lucha de clases y marginales en el campo de lo popular. 
la perspectiva analítica sobre las prácticas contestatarias y las movilizaciones barriales considerando la cohesión simbólica detrás de las movilizaciones sociales, la intersección pluriclasista de los protagonismos urbanos ${ }^{3}$, la diferencia cultural en la disputa de los espacios públicos, la emergencia de diversos colectivos ciudadanos que congregan intereses y acciones comunes, o el episódico protagonismo de las organizaciones barriales.

Ampliar el horizonte analítico de las luchas contestatarias es necesario también debido a la dispersa tendencia temática de los estudios sociales urbanos, en particular a la escasa investigación sobre movimientos populares y organización poblacional en Quito ${ }^{4}$. Evitaré caer en la tentación de caracterizar por medio de adjetivaciones lingüísticas del tipo "pos" aquello que no se conoce suficientemente, no solo porque la realidad social de la urbe se haya desplazado, necesariamente, desde un inexistente y utópico proyecto popular urbano hacia un nuevo escenario de plurales intereses, actorías y proyectos de ciudad, bajo el supuesto de que las dinámicas sociales han traspasado el horizonte de la modernidad urbana, sino porque el conocimiento académico disponible limita una adecuada y realista comprensión de las luchas contestatarias en la ciudad, en razón de lo cual las argumentaciones que hago son a título propositivo.

\section{Heteronomía política y simbolismo urbano}

Los movimientos sociales en tanto formas de canalizar los conflictos en la modernidad colonial, son sistema de narraciones y registros culturales por los que se expresan socialmente los conflictos y las expectativas de reforma

3 Las luchas urbanas a diferencia de las movilizaciones obreras y campesinas, se caracterizaron porque su dinamismo estaba en correspondencia con la intervención de los distintos estratos sociales de los barrios, con el encuentro público del movimiento estudiantil de clase media, de activistas profesionales que con la crisis del sindicalismo se trasladaron al movimiento barrial, con el apoyo de los liderazgos de los partidos de izquierda, y en algunas coyunturas con las adhesiones de los estratos medios de la ciudad.

4 La investigación social urbana de Quito ha tenido olas episódicas de interés temático, carece de continuidad y acumulación mostrándose temporal y espacialmente dispersa. Se concentró en los años ochenta en el estudio del crecimiento urbano, los asentamientos humanos, la conformación de organizaciones barriales y las estrategias de sobrevivencia; en los años noventa pasó a una suerte de condensación temática en torno a la conservación patrimonial de los bienes edificados del centro histórico; y en años recientes están apareciendo variados estudios sobre inseguridad urbana, participación popular, transporte, imaginarios e identidades urbanas, jóvenes y juventud, racismo y discriminación, comunas y estructura social en barrios populares, y territorios y asentamientos humanos que contribuyen a ampliar el espectro de conocimientos académicos sobre las dinámicas sociales de la ciudad. 
de la sociedad, donde los actores colectivos constituidos en movimiento social se adaptan, enfrentan o negocian sus intereses en marcos institucionales (Ibarra y Tejerina, 1998).

En la ciudad de Quito, en dichos años, se dieron coyunturas de convergencia o condensación de los registros o conectores culturales, en los que se involucraron importantes contingentes de personas y organizaciones residentes o en tránsito en la urbe, que les permitieron entrar en interacción creando sentidos compartidos de cohesión y pertenencia territorial, lograr consensos en torno a valores y prácticas ciudadanas de convivencia, al igual que negociar intereses y expectativas de cambio que pusieron en marcha dispositivos de acción colectiva.

Como lo han establecido diferentes autores, no es suficiente con entender los conectores culturales como espacios de interacción específicos y correspondientes a situaciones singulares, sino también el sistema completo de significación en el que están conectados, del que obtienen y al que envían significados colectivos (Tejerina, 1998, p. 120); es decir, en nuestro caso, comprender la singularidad de los dispositivos culturales que operaron en la sociedad quiteña, especialmente en ciertas coyunturas de relevancia política en las que se ratificó el modo de vida capitalino y sus nexos de significación heterónoma con la sociedad ecuatoriana, al igual que las formas de organización barrial y sus vínculos con el poder regional.

El poder regional alude al mayor grupo de interés quiteño constituido por las antiguas familias nobiliarias y hacendarias, devenidas en empresarios inmobiliarios, financieros y comerciales con influencia económica y política en la denominada región Sierra centro norte del país (Saint-Geours, 1994), quienes por medio del control del municipio y de una política urbana concertada establecieron el carácter urbano, económico y simbólico de la expansión metropolitana de la ciudad.

Las conexiones culturales que activaron la interacción política entre personas, organizaciones e instituciones en la ciudad, aunque no son ajenas al poder regional, están estrechamente relacionadas con maneras de comprender los espacios públicos, con narraciones compartidas entre los sujetos sociales acerca de la ciudad, su gobierno, el poder, la convivencia y el territorio; podría decirse que están relacionadas con modos epistémicos claramente influyentes en las conciencias asociativas y categóricos en la acción colectiva. No estoy afirmando que las ideas determinan mecánicamente la práctica, sino que los intereses colectivos que movilizan colaborativamen- 
te a las personas y las formas organizativas que asumen, están relacionadas también con maneras de ser, percibir y sentir el poder local.

En Quito, al igual que en muchas ciudades, la racionalidad urbana capitalista moldea las formas de percepción-conciencia-acción y delimita el horizonte de las prácticas colectivas, las formas de organización y lucha barrial; concomitante, las movilizaciones poblacionales tienden a exhibir algún tipo de agenda institucional o sistémica, manejan un repertorio de medios de presión y mecanismos para su consecusión, buscan congregar la mayor cantidad de relaciones con otros grupos en similar situación, y aunque reconocen liderazgos, tienden al anonimato de sus miembros.

Las formas de acción racional con arreglos medios-fines se recrean en las movilizaciones urbanas en buscan de bienes y servicios bàsicos que mejoren las condiciones de vida, en una suerte de realismo urbano que procesa los problemas de segregación espacial, exclusión cultural y carencias materiales como limitantes de la convivencia en la ciudad. En los sectores populares quiteños estos problemas se asumieron como privaciones que pueden modificarse, combinando la presión de las movilizaciones barriales con la reactividad de las autoridades locales y que decurren, generalmente, en contextos de intercambio político de lealtades vecinales por servicios públicos. Sin dejar de ser clientelismo, el pragmatismo barrial es asumido también como una suerte de oportunidad basada en la experiencia organizativa.

En las luchas populares predominó la racionalidad de corto plazo, aunque también se intersectaron otras "lógicas" de sujetos poblacionales que se encuentran en tensión con el patrón urbano moderno y son portadoras de experiencias forjadas desde la alteridad -como los pueblos indígenas de la ciudad, los grupos de afrodescendientes, las colectivos de mujeres, y las diversas identidades juveniles-, en las que se entrelazaron demandas de modernización con expectativas democráticas por una ciudad inclusiva, y que abrieron perspectivas interculturales a la acción colectiva, proyectándola más allá de la inmediatez del pragmatismo.

No obstante, las distintas movilizaciones sociales que acaecieron en Quito en el transcurso de las décadas señaladas, estuvieron estrechamente ligadas con visiones políticas compartidas o en tensión sobre el simbolismo metropolitano de la ciudad, forjado desde las elites quiteñas y replicado en versión popular entre las clases medias y en los barrios periféricos; y con prácticas convergentes o en resistencia sobre el sentido de la convivencia en la capital, cuyos variados significados culturales estuvieron, y están, en la 
raíz de las luchas contestatarias. Durante los indicados años, sinnúmero de habitantes de Quito se movilizaron políticamente con ciertas percepcionesconciencias sobre los principales hechos urbanos, levantaron agendas compartidas que combinaron demandas de acceso a servicios básicos, legalización de tierras, usos interculturales de los espacios públicos, y la defensa política de la capitalidad; y protagonizaron en unos casos luchas interclasistas con intensas repercusiones políticas.

No exagero al señalar que en el trasfondo de las movilizaciones quiteñas del período, prevaleció la adscripción al sentido modernizante de lo metropolitano que fue compartido por amplios sectores sociales en la ciudad, en el que sobresalió una predisposición idiosincrática a la apropiación criolla, vernácula, del modo de vida de las grandes urbes occidentales, asumiéndolas como la imagen de futuro o el ideal deseado de ciudad. Las autoridades locales, los medios de comunicación, los líderes políticos, las agrupaciones gremiales, las universidades, las organizaciones no gubernamentales, las organizaciones poblacionales y en general la mayoría de las gentes quiteñas concordaron en un discurso de ciudad con imágenes superpuestas, esto es una urbe planificada con vías de circunvalación y monumental, una ciudad empresarial con megas centros comerciales estratificados según el consumo y mercados segmentados, y una ciudad democrática con habitantes cultores de la libertad individual (Hall, 1996).

Al igual que los estratos sociales de las clases media y alta de la ciudad los sectores populares impactados por el avance modernizante también anhelaban, a su modo, el modelo de ciudad con imágenes superpuestas. Entre ellos están los habitantes de los barrios del sur, de los barrios en las periferias urbanas y periurbanas circundantes, de los barrios formados por cooperativas con tenencia informal del suelo en ex haciendas, de asentamientos humanos en quebradas, hondonadas y zonas de riesgo, de las comunas indígenas acorraladas por la expansión urbana, en algunos de los cuales pervive en la mayoría de sus moradores la expectativa de mejorar sus ingresos y cambiarse de barrio. La ciudad deseada de imágenes superpuestas se parece más, con las diferencias de contextos y escala, a la "ciudad de la difícil equidad" (Hall, 1996), donde sobreviven las colectividades que se encuentran en aparente tensión con la modernidad capitalista.

En el período en referencia, la ciudad afianzó la expansión urbana y un agresivo avance de la racionalidad del progreso. Se ahondó la tendencia a la renovación urbana por la que el centro de la vieja ciudad, los barrios tradi- 
cionales y antiguas zonas residenciales peri-centrales dieron paso a novísimas áreas productivas, comerciales y de servicios, o la apertura de vías que enlazan los valles circundantes provocando desplazamientos poblacionales y modalidades de centrifugación social con nuevas segregaciones urbanas. La mancha urbana se expandió desproporcionadamente, sometiendo a la ruralidad con todas las consecuencias de mutación del hábitat, el territorio, las economías solidarias y las formas de vida, cuyas expresiones culturales, en el mejor de los casos, son encapsuladas en el folklore urbano.

La racionalidad moderna no solo modificó la morfología de la ciudad, sino que sometió a los diferentes epistemes y sabidurías populares, a las distintas iniciativas de organización popular y a las preexistentes formas de acción comunitaria, unificándoles en una estandarizada manera de movilización y organización social que evoluciona hacia la ciudadanización funcional al "liberalismo individual" (Díaz-Polanco, 2007) que ve en lo comunitario, en lo cooperativo, en lo asociativo y en lo vecinal, vestigios de un pasado tradicional obstáculo del progreso. En las movilizaciones sociales se superpusieron actores, discursos, liderazgos e identidades culturales, en medio de la polarización entre el carácter colectivo de la reproducción social y la funcionalidad individual de la producción mercantil.

En este sentido, la capital del país fue el locus de un amplio espectro de movilizaciones urbanas de distinta naturaleza, que en el período de conformación del distrito metropolitano activaron a diversas actorías sociales, algunas incluso con intereses antagónicos, emergiendo sinúmero de prácticas contestatarias populares desde barrios urbanos diferenciados y con temporalidades superpuestas. Fueron movilizaciones que bajo determinadas condiciones políticas pasaron de seguir cursos paralelos, indiferentes entre sí, a entrecruzarce y protagonizar, en los últimos años, fugaces convergencias contestatarias.

A las movilizaciones quiteñas acaecidas en el período de conformación del distrito metropolitano, les catalogo en tres tipos: las relacionadas con el auge y decline del movimiento barrial o poblacional, las vinculadas a las disputas culturales del espacio público por actorías subalternas, y las que se activaron en el ciclo de movilizaciones urbanas en defensa de la capitalidad lideradas por las élites quiteñas.

Las luchas relacionadas con el augue y decline del movimiento barrial, refieren al proceso de organización y movilización poblacional en los barrios populares de Quito, como expresión de un vacilante movimiento barrial que levantó una ola de crecimiento organizativo en torno al acceso a 
la vivienda, el mismo que fue eclipsado y desactivado por las maquinarias clientelares locales, o por la pérdida de vigencia de sus organizaciones.

Con las disputas por el espacio público desde la subalternidad, me refiero a las luchas protagonizadas por los Otros habitantes de la ciudad que son culturalmente estigmatizados, y que se cristalizaron en diversas acciones de las poblaciones indígena, afrodescendiente, mujeres y jóvenes que demandaron espacios de participación ciudadana y convivencia intercultural ante la discriminación, segregación y violencia de que son objeto, presionando por nuevos usos colectivos de los espacios públicos como ejercicio del derecho a la ciudad.

Y en el ciclo de defensa de la capitalidad, en cambio, aludo a las movilizaciones urbanas ocurridas entre los años 1992 al 2005 que fueron encabezadas, direccionadas o manipuladas por las elites y clases acomodadas quiteñas, quienes desde las instituciones privadas, ancladas en el municipio y ejerciendo presión político-cultural, congregaron a amplios sectores medios y populares en defensa de la capitalidad, adquiriendo notoriedad en las multitudinarias movilizaciones ciudadanas que derrocaron a tres presidentes y legitimaron los golpes de Estado.

\section{Los espacios públicos diferenciados}

En Quito hay un complejo entramado de relaciones heterónomas del poder regional con el Estado-nación ecuatoriano, del cual forma parte el municipio capitalino tradicionalmente dirigido por autoridades de estirpe aristocrática hacendaria devenida contemporáneamente en empresariado inmobiliario, financiero y comercial, que proyectó un discurso, aparentemente disfuncional, acerca de Quito como una "pacífica ciudad conventual", con la que se encubrió la segregación urbana de la capital. La consecuente política urbana regló el territorio y el discurrir inequitativo de bienes, servicios e imaginarios que permitieron una tensa coexistencia de barrios, colectividades, comunidades e individualidades.

La disfuncionalidad ahondó las ilusiones movimentistas y el realismo organizativo del movimiento barrial quiteño, en el que coexisten imágenes contradictorias de un lejano pasado de levantamientos barriales, y de una ciudad "pacífica y conventual" que no encajaron con las movilizaciones barriales del período, pero que se usaron como conectores simbólicos que alegan una con- 
tinuidad de rebeliones en las luchas barriales. La retórica barrial de "rebeldía pacífica" pervivió en la memoria colectiva metropolitana y se proyectó, episódicamente, en las reservas morales de sus habitantes impeliéndoles en determinadas coyunturas de malestar público, a blandir banderas y proclamas de subversión ciudadana. Sin dejar de ser una señal del desencaje entre las expectativas por configuraciones societales avanzadas y la primaria realidad organizativa barrial, la retórica de rebeldía pacífica es una suerte de "patente de corso" o potestad heredada para las movilizaciones callejeras.

El solapamiento retórico entre las reminiscencias de las rebeliones barriales ocurridas en la colonia (Paz y Miño, 2014) y la paz franciscana de Quito, funcionó como una ideología barrial que naturalizó la explicación de determinados comportamientos culturales y políticos de sus habitantes, reduciéndoles a una idiosincracia callejera y vecinal propia del retraimiento andino. Desconoce el complejo entramado de relacionamientos de poder entre las clases sociales urbanas, los encontrados intereses sectoriales y gremiales en disputa, y las jerárquicas negociaciones entre actores sociales en condiciones material y culturalmente desiguales, y les atribuye, llanamente, un supuesto carácter volcánico, impredecible, a los barrios y habitantes de la capital. Asumida ideosincráticamente en amplios círculos capitalinos, la retórica de la rebeldía pacífica fue usada como advertencia del potencial reactivo quiteño, especialmente en determinadas coyunturas de descontento político que estimularon escaladas del malestar ciudadano.

La analogía de rebeldía pacífica haciendo suyo el complejo de inferioridad colonial (Kingman, 2014), corroboraba que los alzamientos barriales solo ocurren ante graves crisis nacionales, asumía que en la cotidianeidad de la vida capitalina predomina la tranquila convivencia de sus habitantes en el que la discriminación racial, el prejuicio ante la diferencia cultural y la exclusión derivada de la pobreza, son propias de la segregación urbana. En esta visión se admite que Quito es una ciudad apacible, que sus barrios se prestan de una tranquila coexistencia, pero cuando por razones del "mal gobierno" se condensan las crisis políticas que alteran sus pacíficas costumbres, se activan los dispositivos simbólicos que movilizan a los barrios para restaurar la calma y el funcionamiento "normal" de la sociedad quiteña

Y es que lo local en el ámbito metropolitano está relacionado con la conformación y disputa de los espacios públicos de la ciudad, donde se sintetizan el orden y las jerarquías del poder, los lugares, la cohesión social, los intercambios económicos y culturales, y en los que la sociedad urbana en su 
diversidad y heterogeneidad se expresa (Borja, 2011, p. 321). Condicionados por la ciudadanización de las políticas urbanas y la gestión de la ciudad, los espacios públicos rebelan las tensiones entre los lugares y no lugares entretejidos, al mismo tiempo separados, por las dinámicas del capital financiero e inmobiliario que prioriza las áreas de inversión y expansión urbana, y las áreas prescindibles que fueron residualmente incorporadas por medio de redes inmobiliarias.

Durante varias décadas en el Distrito Metropolitano de Quito no se configuró un mismo y único espacio público en el que se exprese pluralmente la diversa sociedad local, sino que, paradójicamente, se instituyeron disímiles espacios públicos diferenciados culturalmente por la segregación urbana, en los que simbólica y discursivamente prevalecieron los intereses particulares relacionados con el poder regional, por sobre los disímiles intereses colectivos relativos al vivir bien en la ciudad y eventuales propuestas de democratización urbana.

Mientras las clases acomodadas expresaron públicamente sus protestas y oposición al "mal gobierno" dentro de un perímetro delimitado de la ciudad moderna, valorada económica y culturalmente como una extensión habitual de lo privado que confirió un simbolismo cohesionador a determinados parques y avenidas del centro norte, y de los valles circundantes nororientales; las clases populares, las organizaciones barriales y poblacionales en sus demandas de servicios, infraestructura y legalización de tierras se movilizaron por la extensa ciudad "sureña", por los costados y periferias urbanas, superponiendo prácticas colectivas, comunitarias e individuales que también confirieron simbolismos integradores a otros sitios en la ciudad.

En cambio, los colectivos de las minorías sociales que se expresaron desde el antagonismo del no lugar en los sititos racializados o estigmatizados por la sociedad, que viven con el riesgo de ser señalados cuando transgreden el simbolismo de la ciudad moderna, protagonizaron protestas y demandas públicas circunscritas al ámbito de lo barrial o comunitario, en una suerte de micro enclaves culturales. Son los sitios de residencia de grupos humanos que expresan la heterogeneidad extructural y la diferencia cultural de la sociedad quiteña, a los que se estigmatiza como inferiores por atávicos dispositivos discriminatorios que racializan la segregación urbana. Diríamos, usando la expresión de Franz Fanon (1991), que son los lugares de asiento de los "condenados" de la ciudad, de aquellos que resisten en preexistentes y nuevas espacialidades configuradas desde la alteridad cultural, 
y que contrastan con la imagen generalizada de que la capital presenta las mejores condiciones de vida del país.

Asimismo, en el curso de dichos años, el Centro Histórico también se ratificó como el mayor espacio público de expresión popular, por estar ahí las sedes de los gobiernos nacional y municipal, y cuando en sus plazas y calles convergieron las distintas movilizaciones sociales de las clases acomodadas y sectores populares en las coyunturas de alta activación política.

En los espacios públicos del distrito metropolitano se expresaron las disímiles realidades barriales, las desiguales intervenciones municipales de hábitat y las contradictorias existencias culturales de su población. Las condiciones objetivas de vida en la ciudad detonantes de las luchas sociales de conformidad y apego al orden, o de disconformidad con la política urbana, son diferentes entre los barrios patricios bien equipados y los barrios populares mal integrados a la urbe, entre los barrios antiguos en decadencia y los nuevos barrios cerrados que se expanden sobre las comunas indígenas circundantes, entre el crecimiento en altura en áreas exclusivas de renovación urbana y el crecimiento horizontal de masividad habitacional, entre la ruralidad expulsada y el urbanismo desbordado.

Y es que la ciudad metropolitana quiso ser, tal vez todavía pretende ser, simultáneamente el lugar de realización de la acumulación e individualización capitalista, y de la posibilidad del cambio sistémico urbano, gestado desde formas de autogobierno local que estén efectivamente cercanas a la gente y enraizadas en procesos de acción colectiva, con las que se levanten niveles superiores de agregación de intereses colectivos, más allá de las demandas inmediatistas de las organizaciones vecinales, o del individualismo ciudadano de las clases acomodadas, con horizontes democratizadores del territorio y los espacios públicos.

La promesa de movimientos urbanos anti-sistémicos o de una "sociedad civil" quiteña, son expectativas que demográficamente todavía moran en el ámbito de las teorías regulatorias o emancipatorias, porque en la praxis de la ciudad, donde se concreta la existencia social, hay más bien una tendencia a la segmentación de la población como consecuencia de las interpelaciones que hacen las políticas públicas locales. Asimismo, en los estratos populares movilizados por el acceso a los servicios e infraestructura urbana, prevaleció un carácter pragmático de la organización en barrios, comunas, cooperativas, comités y sectores que se mostró distante de otras formas de asociación poblacional con mayor alcance, y puso en evidencia la disloca- 
ción entre una práctica limitada de las organizaciones barriales y las amplias expectativas asociativas de un movimiento popular urbano.

La distinción entre ciudadanía y población es pertinente, en el sentido de que en el discurso de la ciudad la soberanía popular está asociada con la noción de ciudadanía, sobre la que se construye una identidad urbana homogénea, mientras que la acción estatal y municipal requieren de categorizaciones combinadas de la población para la implementación de la política urbana que ratifican el carácter heterogéneo de lo social.

En la ciudad la distinción entre ciudadanía y población evidencia la tensión entre el imaginario político de la soberanía popular, y la realidad gestionada mundanamente por el municipio, la que se materializa en la diferenciación del espacio público uniforme y bien atendido de la ciudadanía integrada, y los espacios públicos precarios y mal atendidos de la población segregada; pudiendo afirmarse que en la ciudad se rebelan espacial y simbólicamente lo que Chartterjee denomina como "el quiebre entre lo nacional homogéneo y lo social heterogéneo (2008, p.191).

\section{El ciclo del movimiento barrial quiteño}

Es un hecho cierto que a partir de la segunda mitad del siglo XX las dinámicas de crecimiento organizativo del amplio espectro de organizaciones, actores y acciones que conforman el movimiento popular urbano, grosso modo han sido concomitantes con las tendencias del crecimiento urbano metropolitano que trajo aparejado el aumento de los barrios populares, de su población y expectativas de vida, así como de las experiencias organizativas para la consecución de sus necesidades (Unda, 2008, p. 11).

No obstante, las relaciones entre la expansión urbana y el movimiento barrial no siguieron un curso unívoco de evolución organizativa conforme el crecimiento de la ciudad, sino que en el contexto estructural de una tendencia de continua y desbordada expansión urbana, intensificada en determinadas coyunturas nacionales de bonanza económica, el movimiento barrial quiteño experimentó una ciclo que tiene como trasfondo el surgimiento de nuevos barrios periféricos y la expansión de la ciudad, y cuyo dinamismo está en referencia al encuentro público con los agentes externos y otros movimientos sociales y políticos, diferenciándose tres grandes períodos concatenados entre sí por fases internas de transición. 
El primer período empieza desde mediados de los años cuarenta con el paso de la ciudad de castas, patrimonial y tradicional a una urbe más moderna, cuando las autoridades municipales promovían la creación de "comités de adelanto o pro mejoras", ligas deportivas barriales y parroquias rurales, como nuevas formas de mediación social distantes de las tradicionales cofradías, gremios de profesionales y obreros católicos, y como parte de la estructura de funcionamiento político del partido liberal en la ciudad (Goetschel, 1992).

Las movilizaciones barriales por servicios e infraestructura no cabían en la cultura cívica heredada, las nuevas organizaciones estaban condicionadas por el estilo epistolar, el personalismo de la dirigencia barrial y la influencia clientelar de los tradicionales partidos políticos, por lo que las organizaciones barriales a más de las innumerables cartas con peticiones eventualmente pedían audiencias para asistir a las reuniones del cabildo y exponer sus demandas.

La narrativa que cohesionaba a los miembros de las organizaciones era la vecindad que, de origen colonial y acuñada en la identidad mestiza de los barrios tradicionales del centro de la ciudad, homogeneizaba a todos los habitantes de los barrios periféricos por su condición de propietarios, y se caracterizó por una relación voluntarista de los barrios con el municipio que era afín con la imagen de "pacífica ciudad". El aparecimiento de nuevas organizaciones barriales al sur de la ciudad, mostró obsoletas a las organizaciones vecinales, y abrió una fase de transición cuando el personalismo de la dirigencia barrial fue desplazado por la movilización popular influenciada por el movimiento estudiantil y los partidos de izquierda, a fines de los años setenta.

El segundo período comienza a inicios de la década de los años ochenta con la expansión del movimiento barrial, estimulado por la concurrencia de nuevos actores colectivos, organizaciones populares y agentes promotores en el contexto de la transición democrática y el aparecimiento de nuevos partidos políticos que disputan los gobiernos municipal y provincial. El encuentro en los espacios públicos del movimiento barrial con otros actores colectivos marcó al período, entre los cuales destacaron las comunidades eclesiales de base que promovieron la formación de comités en los barrios periféricos del sur y centro de la ciudad, con una agenda de articulación política entre las fuerzas populares urbanas (Borja, 2011).

Los nuevos partidos políticos también ingresaban a los barrios populares para disputar a los partidos tradicionales y reorganizar las maquinarias clientelares, desdibujándose los contornos entre los comités barriales y los 
comités electorales. Asimismo, la población de los barrios periféricos empezó a evidenciar su propia complejidad societal, con lo que el registro de vecindad fue reemplazado por la nueva narrativa de lo poblacional, que abarcaba la riqueza socio-organizativa del mundo barrial, la heterogeneidad estructural y la diversidad cultural de sus habitantes.

Algo inédito ocurrió en el movimiento poblacional quiteño con la formación de las organizaciones barriales de nivel federativo, organizaciones de segundo grado, que bajo la denominación de federaciones, cooperativas y uniones buscaban representar zonalmente a los barrios con agendas que iban más allá de las demandas inmediatistas de infraestructura urbana, interpelando la política urbana concertada con una agenda de reivindicaciones urbanas (Gracia, 1985), y protagonizaron numerosas luchas contra la cota de altura urbanizable, emplazamientos inadecuados de plantas industriales en los contornos de los barrios periféricos, el hospital del sur, la defensa de los mayores espacios verdes ahora constituidos como parques metropolitanos, entre otras.

Aunque las federaciones trataron de agregar agendas zonales de los barrios y representar a la heterogeneidad poblacional, en la práctica no lograron integrar a la compleja y diversa población barrial, con lo que protagonizaron intensas movilizaciones barriales ante el municipio, logrando el pico más alto de organización y lucha barrial, hasta que se desaceleró y entró en una nueva fase de transición con la pérdida de vigencia de las organizaciones barriales, a fines de la década de los noventa.

El tercer período empieza en los años dos mil con la generalización de una tendencia de reflujo del movimiento barrial provocado por su erosión organizativa, la universalización del clientelismo barrial asociado a la crisis de representatividad de los partidos políticos, y el repliegue de las organizaciones populares y los agentes promotores. Paradójicamente, el eclipse de la organización barrial ocurrió conjuntamente con el período de auge del movimiento indígena que protagonizó sucesivas marchas y tomas simbólicas de la ciudad de Quito, y con la incipiente experiencia de participación ciudadana municipal.

El municipio de Quito implementó el Sistema de Gestión Participativa a través de las Administraciones Zonales, convocando a la población a participar en cabildos temáticos y territoriales para analizar y decidir sobre las agendas locales, en las que se superpusieron y confundieron las organizaciones barriales y las instancias de participación, generándose tensiones entre 
los comités, las federaciones y los cabildos temáticos y territoriales (Torres, 2002). Planteada la participación como un derecho ciudadano, el registro de lo poblacional fue reemplazado por la narrativa de la ciudadanía, con lo que en adelante la retórica del movimiento barrial quedó atrapada en la construcción de la ciudadanía.

Finalmente, el decline de las organizaciones barriales se dio en un escenario de efervescencia social por la movilización de las clases medias y altas de la ciudad en defensa de la capitalidad, en el que protagonizaron sendas movilizaciones pluriclasistas con las que se derrocaron tres gobiernos, en el transcurso de la primera década de los años dos mil y que se prolongaría hasta el final de la siguiente década, sin que haya visos de una nueva fase de transición.

¿Por qué el movimiento barrial capitalino entró en un decline organizativo? La ola organizativa del movimiento barrial quiteño forma parte de la tendencia cíclica de los movimientos sociales, pudiendo establecerse correlaciones entre la expansión urbana y la dinámica del movimiento barrial, pero sus nexos no son mecánicos, ni obedecen a una lógica determinista de la organización territorial sobre la organización barrial, aunque prevalezca el sentido pragmático que motiva la asociatividad vecinal. No es que el urbanismo o el ordenamiento territorial regla las formas de organización social, ni que siempre o necesariamente a una mayor expansión urbana le corresponde un aumento del movimiento barrial; se trata más bien de la relación heterónoma, inacabada, del poder regional de la ciudad con sus barrios y zonas, en la que el gobierno local recibe demandas desde los barrios populares y organizaciones vecinales, a los cuales, en respuesta les confiere condiciones materiales y sentidos culturales de integración o segregación urbana.

La transitoriedad de la organización barrial también esta relacionada con su anclaje en el carácter relativo de los barrios, respecto de la estructura del poder de la ciudad. Los barrios populares, sus organizaciones y la ciudad de Quito se influyen sistémicamente en el proceso de organización territorial metropolitano que ahondó la congénita segregación norte-sur, reproduciéndola también al interno de los entornos peri-centrales y en las nuevas centralidades de los valles circundantes, reconfigurándose, en la relación centro urbano-periferia, el acoplamiento inconcluso y transitorio de la ciudad con los barrios populares.

Lefebvre argumentó que en los barrios no se forman ni instituyen los principales roles sociales, ni las conductas o los comportamientos comunes, 
ni siquiera cuando utilizan la territorialidad para imponerse, el barrio no interviene en la creación de valores dominantes y prácticas fundacionales de ciudadanía (Lefebvre, 1978, p. 197), estos se generan en otros ámbitos e instituciones urbanas como la educación y la escolaridad, la economía y el mercado, el Estado y la política, el poder y la sociedad; y si bien pueden darse condiciones políticas y culturales para que en los barrios emerjan efervescencias de luchas poblacionales, las instituciones fundantes tienen poco en común con los barrios, contrariamente, los exceden y determinan.

Los barrios populares como espacios sociales mínimos configurados incompletamente por las instituciones del poder regional y los centros urbanos, tienen existencias transitorias aunque en su interior se constituyen relaciones interpersonales más o menos duraderas y profundas, en palabras de Lefebvre: "es el más grande de los pequeños grupos sociales y el más pequeño de los grandes", donde la vecindad sustituye las distancias sociales, espaciales y temporales. Los barrios tampoco son unidades autosuficientes, dependen de otros grupos funcionales más amplios que están activos a escala de la ciudad, la región y el país con los cuales se accede a bienes, servicios, ingresos y se configuran las identidades, con lo que "La estructura del barrio depende completamente de otras estructuras más vastas: municipalidades, poder político, instituciones. No es más que una ínfima malla del tejido urbano y de la red que constituye los espacios sociales de la ciudad" (Lefebvre, 1978, p. 202).

La relatividad de lo barrial también se expresa en las relaciones de vecindad que devienen suplementarias respecto de las relaciones productivas, comerciales, de movilidad, y culturales que establecen los habitantes populares de la ciudad, las que suelen ser de mayor dependencia y duraderas, con lo que si bien lo vecinal comparte una naturaleza social basada en el ethos del pueblo y como tal forma parte del campo popular, está sometida a los rápidos cambios de la ciudad que alteran las simetrías habituales entre vecinos, las redes familiares y de afinidad, los barrios y vecindarios, creando condiciones espaciales que involucran a los habitantes en un "continuo y rápido movimiento que transforma los barrios en criaturas híbridas suspendidas entre el pasado y el futuro" (Keller, 1975, p. 30).

La relatividad de lo barrial en la estructura del poder de la ciudad, se evidencia en los barrios populares surgidos, en gran número, como lotizaciones irregulares por los intermediarios inmobiliarios, a quienes vendieron los antiguos propietarios de las innumerables haciendas durante su conversión 
de hacendados en empresarios, contando siempre con el aval del municipio capitalino. En la posterior formación de los barrios populares se combinaban la autogestión vecinal o comunitaria, con parciales y clientelares intervenciones municipales, una episódica asistencia al desarrollo prestada por entidades de la sociedad civil, y las presiones de las organizaciones populares pro vivienda.

Si los barrios no son formaciones naturales de la ciudad, sino configuraciones espacio temporales transitorias, las organizaciones vecinales tampoco son brotes espontáneos de sus moradores, sino dispositivos socio culturales creados en el marco del poder político regional y con vigencia mientras sean útiles para la inserción estable en la ciudad. La brevedad protagónica de la organización barrial en el espacio público urbano, esta relacionada con el carácter temporal de lo barrial respecto del orden y el poder en la ciudad.

En el itinerario de la modernización urbana de Quito, la existencia de diversas organizaciones poblacionales capaces de movilizar a la población para la consecución de las reivindicaciones de los barrios periféricos y populares, obedeció a la convergencia de agentes públicos, privados y de la sociedad civil que promovieron la asociatividad. Fueron decisivas las distintas autoridades locales, especialmente liberales, que indujeron la formación de comités barriales para el acceso a los bienes y servicios públicos, los dispositivos clientelares de los partidos políticos en los barrios que superpusieron o crearon comités partidarios como parte de las maquinarias electorales, la presencia de los agentes externos del desarrollo como las iglesias, entidades de la cooperación internacional y organizaciones no gubernamentales que promovieron las cooperativas de vivienda, y las propias iniciativas de los habitantes para la autogestión de servicios, especialmente cuando compartiendo matrices culturales solidarias forjaron la organización barrial.

Sería voluntarismo pensar que estos agentes e influencias se agruparon intencionadamente para promover la organización del sujeto barrial, al contrario, cada uno de los agentes desplegó su propio protocolo con temporalidades y resultados disímiles, y aunque ocurrieron situaciones extraordinarias de convergencia de algunos de ellos, por lo regular la organización resultante fue consecuencia de la combinación de intervenciones episódicas e incompletas. Asimismo, la influencia de los agentes no fue siempre la misma, varió según las coyunturas políticas nacionales que estimularon o restringieron las experiencias organizativas, las que, internamente, se potenciaban o desincentivan conforme los valores de la cultura política urbana, especialmente de la cerca- 
nía de los liderazgos barriales, vecinales y poblacionales a las prácticas autoritarias y patrimoniales de las elites políticas capitalinas.

El movimiento barrial se constituyó en el encuentro público con otros sectores populares y movimientos sociales, en el relacionamiento con el sistema político y la estructura de la ciudad, lo cual fue posible por los agentes externos que contribuyeron a la creación de organizaciones federativas o de segundo grado, las que posibilitaron la agregación de intereses y la movilización de recursos potenciando al movimiento barrial. El vínculo de las organizaciones vecinales con los agentes promotores y los movimientos sociales, cualificó al movimiento barrial, en tanto proveyó o incentivó la educación popular, el acceso a medios de comunicación alternativa, la capacitación y el liderazgo organizativo, además del activismo y la energía cultural necesarias para animar cotidianamente las asambleas, reuniones, campañas, marchas y demás formas de lucha poblacional.

Así, la caracterización del ciclo del movimiento barrial quiteño precisa considerar que su evolución estuvo condicionada por el encuentro, en los espacios públicos, con otros agentes y movimientos sociales que enriquecieron la organización barrial y ampliaron el repertorio de acción colectiva. $\mathrm{Su}$ vigencia fue correlativa con la lucha pro vivienda y la inserción individual, en la que se asume lo barrial como algo a construir y la ciudad como lo establecido, cuando se consiguieron las reivindicaciones vecinales la organización barrial se desactivó, y en el encuentro con los otros movimientos sociales y políticos cuando estos se replegaron de la escena pública, el movimiento barrial entró en reflujo.

\section{Conclusiones}

Aunque para muchas personas puede parecer controvertido y polémico, en la ciudad de Quito, a comienzos del siglo XXI y luego de más de cuatro décadas de organización barrial, no es claramente visible una trayectoria colectiva de lucha barrial y poblacional lo suficientemente consistente como para alterar o disputar el curso de la modernidad-colonialidad urbana, ni para contribuir desde la sociedad organizada, desde las "bases sociales" dirían unos o "desde abajo" dirían otros, a una democracia territorial o a un sistema político municipal que se proyecte más allá del liberalismo imperante.

El movimiento barrial capitalino atravesó por tres periodos de inicio, auge y decline de la lucha urbana, a los que les correspondieron tres regis- 
tros narrativos: empezó como un movimiento de adscripción vecinal de naturaleza homogénea circunscrito a los propietarios y funcional al poder regional, se expandió conjuntamente con el reconocimiento de la riqueza del mundo poblacional que marcó la diversidad cultural y protagonizó importantes interpelaciones a la política municipal, y declinó junto con la erosión organizativa durante la implementación de la experiencia municipal de participación, con la generalización de la construcción, nuevamente homogeneizadora, de ciudadanía.

Teniendo como núcleo socio-organizativo la lucha por la vivienda e infraestructura urbana, el movimiento barrial no supo, no pudo, incluir a la diversidad de actores, subjetividades y prácticas colectivas existentes en los barrios periféricos y populares, con lo que la creciente dispersión y fragmentación de las demandas ciudadanas y colectivas exigen formas de analizar y comprender las luchas contestarias en la ciudad, distanciándose de la tentación de pensar de que se tratan de nuevos movimientos sociales, y que en realidad son otras expresiones de los conflictos en la ciudad.

\section{Bibliografía}

Borja, Raúl (2011). Los movimientos sociales en los 80 y 90. Quito: Centro de Investigaciones CIUDAD.

Borja, Jordi (2011). Revolución urbana y derecho a la ciudad. 1ra Edición. Quito: OLACCHI, Municipio Metropolitano de Quito.

Carrión, Fernando (1987). Quito crisis y política urbana. Quito: Editorial El Conejo, Centro de Investigaciones CIUDAD.

Chartterjee, Partha (2008). La nación en tiempo heterogéneo y otros estudios subalternos. Argentina: CLACSO, Siglo Veintiuno Editores.

Díaz-Polanco, Héctor (2007). Elogio de la diversidad. México: Siglo Veintiuno Editores.

Goetschel, Ana María (1992). Hegemonía y sociedad (Quito: 1930-1950). En: Eduardo Kingman Garcés (Comp.), Ciudades de los Andes. Visión histórica y contemporánea. Lima: Institut Fracais D’Études Andines.

Lefebvre, Henri (1978). De lo rural a lo urbano. Barcelona: Ediciones Península.

Fanon, Frantz (1991). Los condenados de la tierra. México: Fondo de Cultura Económica.

Hall, Peter (1996). Ciudades del mañana. Historia del urbanismo en el siglo XX. Barcelona: Ediciones del Serbal, 
Ibarra, Pedro y Tejerina, Benjamín (1998). Introducción. En: Pedro Ibarra y Benjamín Tejerina (Ed.), Los movimientos sociales. Transformaciones politicas y cambio cultural (pp. 111-138). Valladolid: Editorial Trotta.

Instituto de la Ciudad (2012). Conociendo Quito. Estadísticas del Distrito Metropolitano No. 3. Quito: Municipio del Distrito Metropolitano de Quito.

Keller, Suzanne (1975). El vecindario urbano: una perspectiva sociológica. Madrid: Siglo XXI Editores.

Kingman Garcés, Eduardo (2014). Oficios y trajines callejeros. En: Eduardo Kingman Garcés y Blanca Muratorio, Los trajines callejeros. Memoria y vida cotidiana Quito, siglos XIX-XX. Quito: FLACSO, Instituto Metropolitano de Patrimonio, Fundación Museos de la Ciudad.

Paz y Miño, Juan (2014). Quito en el Bicentenario del proceso de la Independencia del Ecuador. 1ra Edición. Quito: Abya-Yala, Pontificia Universidad Católica del Ecuador, ADHILAC.

Tejerina, Benjamín (1998). Los movimientos sociales y la acción colectiva. De la produccción simbólica al cambio de valores. En: Pedro Ibarra y Benjamín Tejerina (Ed.), Los movimientos sociales. Transformaciones politicas y cambio cultural (pp. 111-138). Valladolid: Editorial Trotta.

Torres D., Víctor Hugo (2002). La participación ciudadana en Quito. En: Víctor Hugo Torres (Coord.), La participación ciudadana en Quito: miradas plurales. Quito: Abya- Yala, Universidad Politécnica Salesiana,

Saint-Geours, Yves (1994). La Sierra Centro y Norte (1830-1925). En: Juan Maiguashca (Ed.), Historia y región en el Ecuador: 1830-1930. Quito: FLACSO, Corporación Editora Nacional.

Unda, Mario (2008). “Apuntes para la historia del movimiento barrial en Quito”. Primera Parte. Inédito. Quito. 